\title{
Fe-Pt thick-film magnets prepared by electroplating method
}

\author{
T. Yanai, ${ }^{1, a)}$ K. Furutani, ${ }^{1}$ T. Ohgai, ${ }^{1}$ M. Nakano, ${ }^{1}$ K. Suzuki, ${ }^{2}$ and H. Fukunaga ${ }^{1}$ \\ ${ }^{1}$ Graduate School of Engineering, Nagasaki University, Nagasaki 852-8521, Japan \\ ${ }^{2}$ Department of Material Engineering, Monash University, Clayton, Victoria 3800, Australia
}

(Presented 4 November 2014; received 22 September 2014; accepted 29 December 2014; published online 17 April 2015)

\begin{abstract}
Fe-Pt thick-films were electroplated on Ta substrates using a direct current, and the magnetic properties of the film were evaluated. The Fe-Pt films with the thickness from 3 to $23 \mu \mathrm{m}$ were obtained by changing in the plating time from 2 to $20 \mathrm{~min}$. As the as-plated Fe-Pt films had the disordered fcc (face-centered-cubic) structure and low coercivity $(<5 \mathrm{kA} / \mathrm{m})$, we annealed the films at $700^{\circ} \mathrm{C}$ for $60 \mathrm{~min}$. The annealing induced the phase transformation from fcc structure to fct (face-centeredtetragonal) one, and we consequently obtained the $\mathrm{Fe}_{50} \mathrm{Pt}_{50}$ thick-films with large coercivity of approximately $700 \mathrm{kA} / \mathrm{m}$. The large coercivity was observed in the wide thickness range for our experimental conditions. Therefore, we concluded that our prepared Fe-Pt film is one of the attractive thick-film magnets. @ 2015 AIP Publishing LLC. [http://dx.doi.org/10.1063/1.4918698]
\end{abstract}

\section{INTRODUCTION}

Recently, many studies on thick-film magnets have been carried out to develop microactuators and micromotors for MEMS technologies and small-size devices. We have also studied thick-film magnets for Nd-Fe-B, Sm-Co, and Fe-Pt alloys prepared by Pulsed Laser Deposition (PLD) or vacuum arc deposition methods, which have high deposition rates (>several $\mu \mathrm{m} / \mathrm{h}$ ). ${ }^{1-4}$ For applying the thick-film magnets into commercial small-size devices, high economic viabilities, such as high deposition rate and simplicity of fabrication equipment, are required. Therefore, chemical processes such as electroplating methods are preferred over physical processes such as sputtering, PLD, and arc deposition methods. Typical film magnets prepared by electroplating method are Pt-TM $(\mathrm{TM}=\mathrm{Fe}, \mathrm{Co})$ films, and many researchers reported their thin-films and nanowires with high coercivity as a future material for recording media. ${ }^{5-10}$ Although there were many studies on the Pt-TM thin-film magnets with thickness of less than $1 \mu \mathrm{m}$, Pt-TM thick-film magnets with superior hard magnetic properties were rarely reported. ${ }^{11}$ Since demagnetizing field in the film strongly affects their magnetic properties, the thick-film magnets with thickness of several tens of micro-meters are required to apply the film magnets to the small-size devices. ${ }^{12-15}$ In this study, we fabricated Fe-Pt thick-films by electroplating method and evaluated the magnetic properties of the annealed films.

\section{EXPERIMENTAL PROCEDURES}

\section{A. Electroplating of Fe-Pt films}

We carried out the electroplating using a direct current to obtain the Fe-Pt thick-films. The contents of the electrolyte in the plating bath are shown in Table I. We also show the electroplating conditions in Table II. The $\mathrm{pH}$ in the bath was not adjusted. A Pt mesh and a Ta plate were used as the anode and the cathode, respectively. The distance

\footnotetext{
a) Author to whom correspondence should be addressed. Electronic mail: t-yanai@nagasaki-u.ac.jp.
}

between the electrodes was $20 \mathrm{~mm}$, and Fe-Pt films were plated on the Ta plate. The current density and the plating time were controlled by using a computer-aided dc-current source. The bath temperature was kept at $70^{\circ} \mathrm{C}$ during the plating. Consequently, we obtained $75-\mathrm{mm}^{2} \mathrm{Fe}-\mathrm{Pt}$ films (Plating area: $5 \mathrm{~mm} \times 15 \mathrm{~mm}$ ).

\section{B. Annealing of Fe-Pt films}

In order to transform a disordered A1 (fcc) structure of $\mathrm{Fe}-\mathrm{Pt}$ crystalline phase in the as-plated film to an ordered $\mathrm{L} 1_{0}$ (fct) one, we annealed the as-plated films at $700{ }^{\circ} \mathrm{C}$ for $60 \mathrm{~min}$. The temperature was ramped from room temperature to the annealing temperature at the constant heating rate of $100^{\circ} \mathrm{C} / \mathrm{min}$, and then kept at constant for $60 \mathrm{~min}$.

\section{Measurements}

The thicknesses and the compositions of the as-plated films were measured with a micrometer (Mitutoyo CPM15-25 MJ) and a SEM-EDX system (Hitachi High-technologies S-3000),

TABLE I. Components in the plating bath.

\begin{tabular}{ll}
\hline \hline Components & Content \\
\hline $\mathrm{FeSO}_{4} \cdot 7 \mathrm{H}_{2} \mathrm{O}$ & $10 \mathrm{~g} / \mathrm{l}$ \\
$\mathrm{Pt}\left(\mathrm{NH}_{3}\right)_{2}\left(\mathrm{NO}_{2}\right)_{2}$ & $10 \mathrm{~g} / \mathrm{l}$ \\
$\mathrm{Citric}$ acid $\left(\mathrm{C}_{6} \mathrm{H}_{8} \mathrm{O}_{7} \cdot \mathrm{H}_{2} \mathrm{O}\right)$ & $30 \mathrm{~g} / \mathrm{l}$ \\
$\mathrm{NH}_{4} \mathrm{Cl}$ & $25 \mathrm{~g} / \mathrm{l}$ \\
\hline
\end{tabular}

TABLE II. Electroplating conditions.

\begin{tabular}{lc}
\hline \hline Conditions & Value \\
\hline $\mathrm{pH}$ (not adjusted) & Approx. 1.6 \\
Bath temperature & $70{ }^{\circ} \mathrm{C}$ \\
Current density & $1 \mathrm{~A} / \mathrm{cm}^{2}$ \\
Plating time & $2-20 \mathrm{~min}$ \\
\hline \hline
\end{tabular}




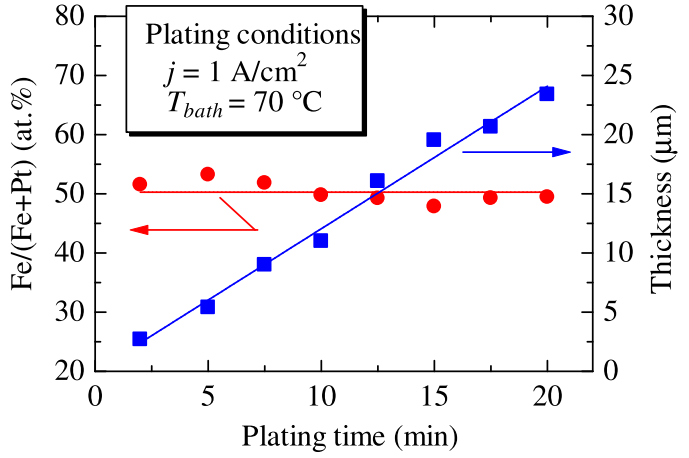

FIG. 1. Thickness and Fe content of the as-plated Fe-Pt films as a function of plating time.

respectively. In the measurement of the thickness, the thickness distribution was observed in the typical plated film. The center thickness of the film was approximately $10 \%$ thinner than the edge one. Therefore, we determined the thickness of the film by averaging the values obtained for approximately every $9 \mathrm{~mm}^{2}$ (9 points) in this study. The hysteresis loops of the asplated Fe-Pt films and the annealed ones were measured with a vibrating sample magnetometer (VSM). The maximum applied field was approximately $2 \mathrm{MA} / \mathrm{m}$ for the measurements of the loop, and we obtained the coercivity of the films from the measured loop. The XRD patterns of the as-plated and the annealed films were evaluated by an X-ray diffractometer with $\mathrm{Cu}-\mathrm{K} \alpha$ radiation (Rigaku Rint 2000).

\section{RESULTS AND DISCUSSION}

Figure 1 shows the thickness and the Fe content of the as-plated Fe-Pt films as a function of the plating time. The Fe content did not depend on the plating time and showed almost constant value of 50 at. \%. The thickness increased with increasing the plating time, and the plating rate, which is calculated by the slope of the linier fitting line, is approximately $70 \mu \mathrm{m} / \mathrm{h}$. From these results, we confirmed that the $\mathrm{Fe}$ content is not affected by the plating time from 2 to $20 \mathrm{~min}$, and found that the $\mathrm{Fe}_{50} \mathrm{Pt}_{50}$ thick-films could be
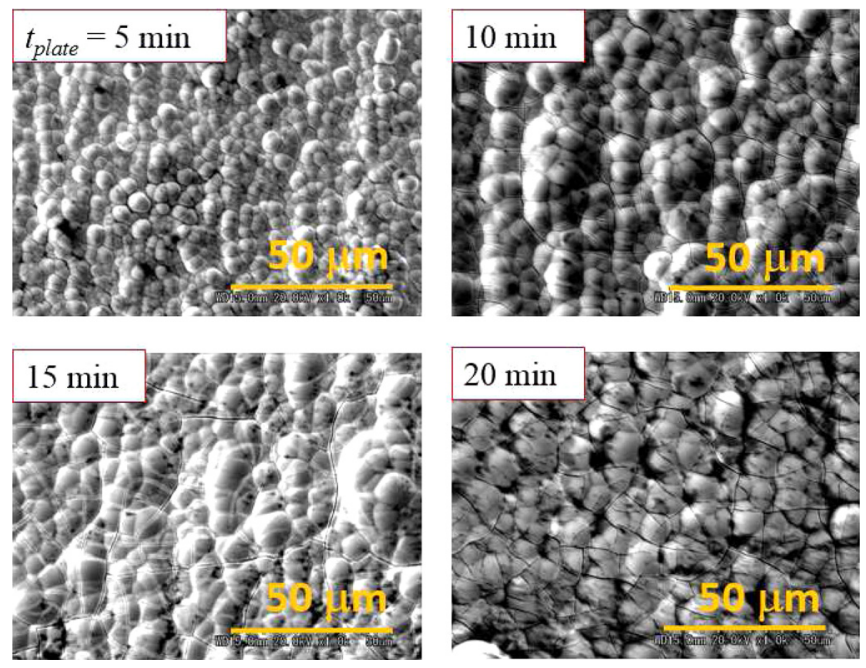

FIG. 2. Surface morphologies of the Fe-Pt films plated for 5, 10, 15, and $20 \mathrm{~min}$.

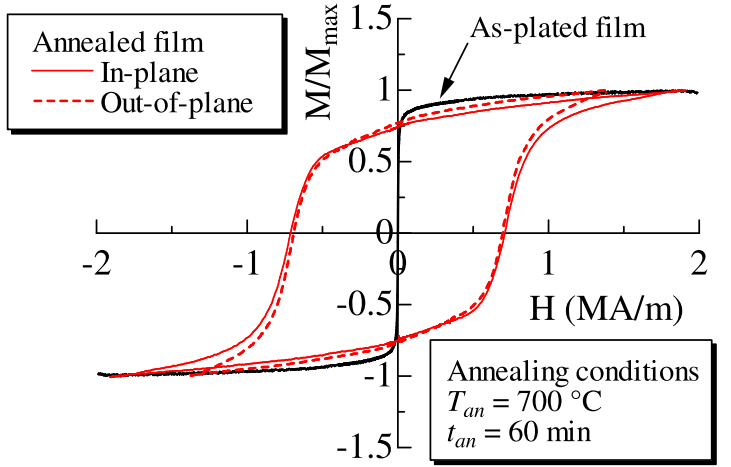

FIG. 3. Hysteresis loops of the as-plated Fe-Pt film and the annealed one.

obtained by the increase in the plating time. Figure 2 shows surface morphologies of the Fe-Pt films plated for 5, 10, 15, and $20 \mathrm{~min}$. The films showed almost the same morphologies, and we observed small cracks in the films plated for 10 , 15 , and $20 \mathrm{~min}$. The presence of the cracks implies the presence of tensile stress in the as-plated films, and we considered that the stress is attributed to hydrogen dissolution in the film. ${ }^{16-18}$

Figure 3 shows hysteresis loops of the as-plated Fe-Pt film and the annealed one. As shown in Fig. 3, the annealed film at $700{ }^{\circ} \mathrm{C}$ for $60 \mathrm{~min}$ had isotropic magnetic property and showed large coercivity of approximately $700 \mathrm{kA} / \mathrm{m}$, whereas the as-plated film showed low coercivity of less than $5 \mathrm{kA} / \mathrm{m}$. This result suggests that the annealing induced the phase transformation from the fcc to fct structures. In order to confirm the phase transformation, we carried out the $\mathrm{X}$-ray analysis for the as-plated film and the annealed one. Figure 4 shows XRD patterns of the as-plated Fe-Pt film and the annealed one. We observed two deflection peaks for the as-plated film except for the peak of the $\mathrm{Cu}$ substrate. As the two peaks were attributed to the fcc structure of the Fe-Pt crystalline phase, we confirmed that the as-plated Fe-Pt film have only fcc structure. On the other hand, many deflection peaks were observed for the annealed film. All peaks were attributed to the fct structure of the Fe-Pt crystalline phase. From the results for Figs. 3 and 4, we found that the annealing advanced the ordering of Fe-Pt crystalline phase and the

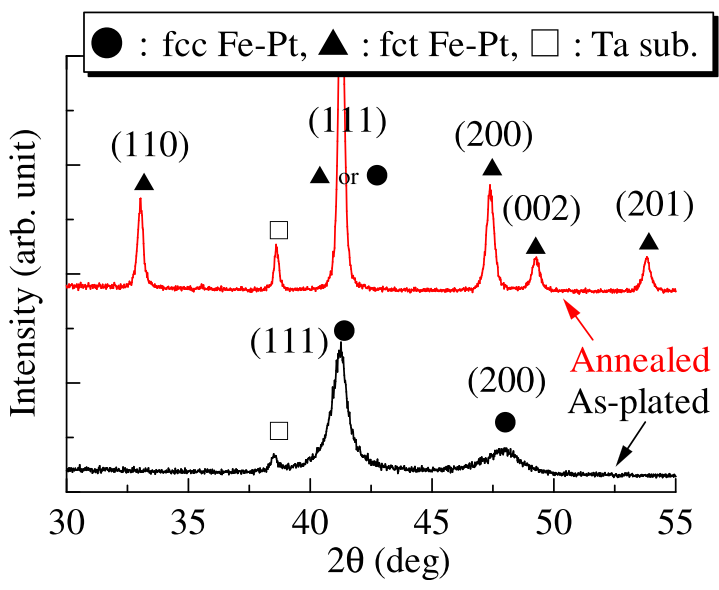

FIG. 4. XRD patterns of the as-plated Fe-Pt film and the annealed Fe-Pt one. 


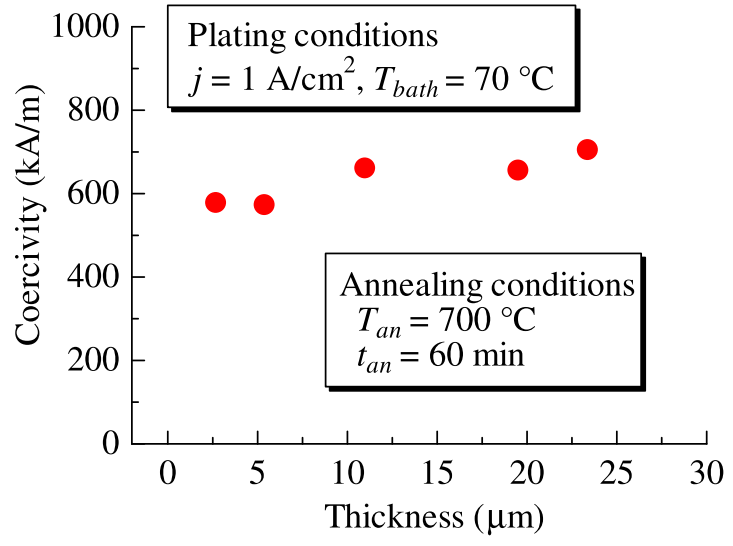

FIG. 5. Coercivity of the plated Fe-Pt films as a function of thickness.

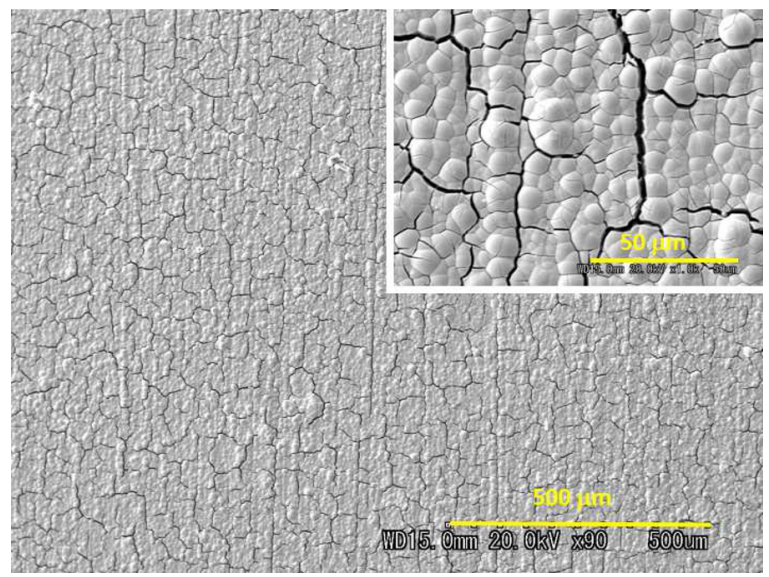

FIG. 6. Surface morphology of the annealed Fe-Pt thick-film.

high anisotropy of the ordered phase caused the increase in the coercivity.

Figure 5 shows the coercivity of the annealed Fe-Pt thick-films as a function of the thickness. The thickness was changed by the change in the plating time. As shown in Fig. 5, we could obtain the Fe-Pt thick-films with high coercivity in the wide thickness range from 3 to $23 \mu \mathrm{m}$. The surface of the annealed thick-film was shown in Fig. 6. Although many large cracks were observed, the Fe-Pt film was not peeled from the Ta substrate. As shown in Fig. 2, the small cracks had been already observed in the as-plated thick-films. We considered that the annealing enlarged the small cracks due to the difference in coefficient of thermal expansion between Fe-Pt films and Ta substrate, and large cracks were resultantly observed in the annealed-films. The reduction in the cracks is one of our future works. From the above-mentioned results, we concluded that our plating bath and plating conditions enable us to obtain Fe-Pt thick-films with high coercivity, and the thick-films are one of the attractive film magnets.

\section{CONCLUSION}

In this study, we investigated the magnetic and the structural properties of the electroplated Fe-Pt thick-films. The obtained results are summarized as follows:

(1) Plating process showed relatively high deposition rate of approximately $70 \mu \mathrm{m} / \mathrm{h}$, and enabled us to obtain $\mathrm{Fe}-\mathrm{Pt}$ thick-films.

(2) Fe-Pt thick-films showed large coercivity after the annealing at $700{ }^{\circ} \mathrm{C}$ for $60 \mathrm{~min}$, and we confirmed that the large coercivity is attributed to the transformation of the Fe-Pt crystalline phase from the disordered fcc structure to the ordered fct one.

(3) Fe-Pt thick-films with high coercivity were obtained in the wide thickness range from 3 to $23 \mu \mathrm{m}$.

${ }^{1}$ H. Fukunaga, T. Kamikawatoko, M. Nakano, T. Yanai, and F. Yamashita, J. Appl. Phys. 109, 07 A758 (2011).

${ }^{2}$ M. Nakano, K. Yamaguchi, T. Yanai, F. Yamashita, and H. Fukunaga, J. Appl. Phys. 105, 07A729 (2009).

${ }^{3}$ M. Nakano, W. Oniki, T. Yanai, and H. Fukunaga, J. Appl. Phys. 109, 07A723 (2011).

${ }^{4}$ M. Nakano, M. Sahara, T. Yanai, F. Yamashita, and H. Fukunaga, J. Appl. Phys. 109, 07A755 (2011).

${ }^{5}$ E. B. Svedberg, J. J. Mallett, S. Sayan, A. J. Shapiro, W. F. Egelhoff, and T. Moffat, Appl. Phys. Lett. 85, 1353 (2004).

${ }^{6}$ K. Leistner, J. Thomas, H. Schlorb, M. Weisheit, L. Schultz, and S. Fahler, Appl. Phys. Lett. 85, 3498 (2004).

${ }^{7}$ K. Ž. Rožman, A. Krause, K. Leistner, S. Fahler, L. Schultz, and H. Schlorb, J. Magn. Magn. Mater. 314, 116 (2007).

${ }^{8}$ F. Wang, K. Hosoiri, S. Doi, N. Okamoto, T. Kuzushima, T. Totsuka, and T. Watanabe, Electrochem. Commun. 6, 1149 (2004).

${ }^{9}$ J. P. Xu, Z. Z. Zhang, B. Ma, and Q. Y. Jin, J. Appl. Phys. 109, 07 B704 (2011).

${ }^{10}$ M. Cortes, E. Gomez, and E. Vallés, J. Electroanal. Chem. 689, 69 (2013).

${ }^{11}$ P. L. Wu, X. H. Li, W. Li, H. Y. Sun, Y. Chen, and X. Y. Zhang, Mater. Lett. 62, 309 (2008).

${ }^{12}$ N. Fujita, S. Maeda, S. Yoshida, M. Takase, M. Nakano, and H. Fukunaga, J. Magn. Magn. Mater. 272-276, E1895 (2004).

${ }^{13}$ G. Pattanaik, D. M. Kirkwood, X. Xu, and G. Zangari, Electrochim. Acta 52, 2755 (2007).

${ }^{14}$ T. M. Selvakumari, R. N. Emerson, and S. Ganesan, Am. J. Appl. Sci. 6, 1175 (2009).

${ }^{15}$ F. M. F. Rhen and J. M. D. Coey, J. Magn. Magn. Mater. 322, 1572 (2010).

${ }^{16}$ I. Mizushima, P. T. Tang, H. N. Hansen, and M. A. J. Somers, Electrochim. Acta 51, 6128 (2006).

${ }^{17}$ A. Krause, C. Hamann, M. Uhlemann, A. Gebert, and L. Schultz, J. Magn. Magn. Mater. 290-291, 261 (2005).

${ }^{18}$ E. Gómez, E. Pellicer, and E. Vallés, J. Electroanal. Chem. 556, 137 (2003). 